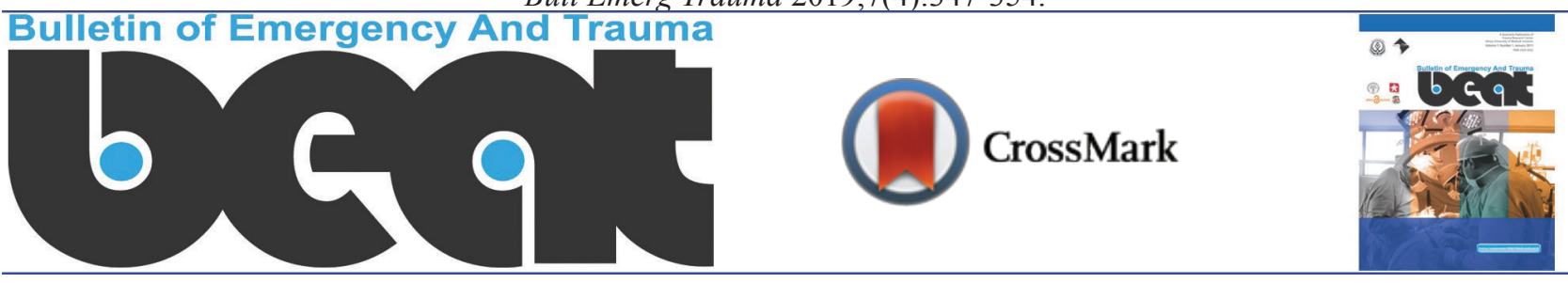

\title{
Development and Validation of a Nomogram for Predicting the Mortality after Penetrating Traumatic Brain Injury
}

\author{
Thara Tunthanathip ${ }^{1 *}$, Suphak Udomwitthayaphiban ${ }^{1}$
}

${ }^{1}$ Division of Neurological Surgery, Department of Surgery, Faculty of Medicine, Songklanagarind Hospital, Prince of Songkla University, Songkla, Thailand

*Corresponding author: Thara Tunthanathip

Address: Division of Neurosurgery, Department of Surgery, Faculty of Medicine, Prince of Songkla University, Hat Yai, Songkhla, Thailand, 90110. Tel: 66-92-5495994, e-mail: tsus4@hotmail.com
Received: March 12, 2019

Revised: July 5, 2019

Accepted: July 20, 2019

\section{ABSTRACT}

Objective: To determine the factors associated with mortality in penetrating brain injury (PTBI) and proposed the nomogram predicting the risk of death.

Methods: A retrospective cohort study was conducted on all patients who had sustained PTBI between 2009 and 2018. Collected data included clinical characteristics, neuroimaging findings, treatment, and outcomes. Prognostic factors analysis was conducted using a forest plot. Therefore, the nomogram was developed and validated. For the propose of evaluation, the nomogram's sensitivity, specificity, positive predictive value (PPV), negative predictive value (NPV), Receiver Operating Characteristic (ROC) curve and the area under the receiver operating characteristic (AUC) were determined for validating the optimal cut-off point of the total scores.

Results: During the study period, 62 individuals enrolled. In the univariate analysis, factors associated with the morality were normal pupils' reactivity to light (OR $0.04, p<0.001$ ), hypotension (OR 9.91, $p<0.001$ ), hypoxia (OR 10.2, $p=0.04)$, bihemispheric injuries (OR 19.0, $p=0.001)$, multilobar injuries (OR 21.5, $\mathrm{p}<0.001)$, subarachnoid hemorrhage (OR 6.9, $p=0.02$ ), intraventricular hemorrhage (OR 26.6, $p=0.006$ ), basal cistern effacement (OR 28.8, $p<0.001)$, midline shift $\geq 5 \mathrm{~mm}(\mathrm{OR} 0.19, p<0.001)$ were significantly associated with death. In multivariable analysis, hypotension $(\mathrm{OR} 8.82, p=0.03)$, normal pupils' reactivity to light $(\mathrm{OR} 0.07$, $p=0.01$ ), midline shift $>5 \mathrm{~mm}$ (OR 18.23, $p<0.007$ ) were significantly associated with death. The nomogram's sensitivity, specificity, PPV, NPV, and AUC for predicting mortality (total score $\geq 100$ ) were $80 \%, 92.6 \%$, $72.7 \%, 95.0 \%$, and, 0.86 respectively.

Conclusion: PTBI is the fatal injury depend on both clinical and neuroimaging parameters. The nomogram is the alternative method providing prognostic parameters toward implication for clinical decision making.

Keywords: Penetrating brain injury; Traumatic brain injury (TBI); Nomogram.

Please cite this paper as:

Tunthanathip T, Udomwitthayaphiban S. Development and Validation of a Nomogram for Predicting the Mortality after Penetrating Traumatic Brain Injury. Bull Emerg Trauma. 2019;7(4):347-354. doi: 10.29252/beat-070402. 


\section{Introduction}

$\mathrm{P}$ enetrating traumatic brain injury (PTBI) is much less common than blunt traumatic brain injury [1]. Larkin et al. reported a prevalence of PTBI in $8.8 \%$ of TBI cases but this injury is significantly more severity and poor outcome [2]. The degree of injury of missile/flak is produced by both lowvelocity and high-velocity projectiles according to the mass-energy equivalence () [3, 4]. Gunshot injuries are the most common cause PTBI and bring high mortality. The mortality rates from gunshot wounds range between $21 \%$ and $88 \%$. [5-9].

Prognostic factors, which included clinical characteristics and neuroimaging features, have been reported in the literature. Bandt et al. proposed the St. Louis Scale for Pediatric Gunshot Wounds to the Head in 2012 [10] while Muehlschlegel et al. proposed the SPIN score in 2016. Similarly, these predictive scores based on physical examination, imaging findings, and laboratory [11]. Additionally, neuroimaging features have been mentioned for predicting mortality and decision-making treatment in an emergency situation [9-11].

Currently, the nomogram has been used to predict clinical outcome in various diseases such as oncology $[12,13]$ and other diseases [14-16]. The model is a mathematical equation that joins the predictors and the outcome of interest with two-dimension graphic scale. The objectives of the current study were to identify various predictors associated with death in PTBI patients and to propose the nomogram to predict mortality.

\section{Materials and Methods}

\section{Study Designs and Study Population}

The authors conducted a retrospective review of the database of our trauma registry. We enrolled consecutive PTBI patients who were treated at the university trauma centers from 2009 through 2018. Several clinical, laboratory, treatment and radiological factors were collected for analysis. Additionally, patients were divided into three groups according to their initial Glasgow Coma Scale (GCS) score: mild TBI (GCS score 13-15), moderate TBI (GCS score 9-12), and severe TBI (GCS score 3-8).

On the basis of neuroimaging, the entry trajectory, intracranial injuries, pressure effect, and other characteristics were reviewed by two neurosurgeons. Bihemispheric injuries were defined as injuries in which the missile/flak track crossed the midsagittal plane, causing injury to both cerebral hemispheres. Multilobular injuries were defined as CT scan evidence of damage to more than one lobe of the brain. In the laboratory, hypoxia was defined as oxygen saturation $<92 \%$ or partial pressure of oxygen $<80 \mathrm{~mm} \mathrm{Hg}$ and anemia was defined as a hemoglobin level below $9 \mathrm{~g} / \mathrm{dl}$ at admission. According to $\mathrm{Wu}$ et al. and clinical practice at our institute, coagulopathy was defined as thrombocytopenia (platelet count $<100,000 / \mu \mathrm{l}$ ) or elevated international normalized ratio $>1.2$ or prolonged activated partial thromboplastin time $>40$ seconds at admission [17, 18]. At the time of hospital discharge, the morality of the patients was considered as the primary outcome of the study. The study was performed with the approval of the Ethics Committee of the Faculty of Medicine, Songklanagarind Hospital, Prince of Songkla University (REC.62-012-10-1).

\section{Nomogram Development and Validation}

Using binary logistic regression analysis, the prediction model was constructed from the significant parameters that affect the mortality. A nomogram, which based on the binary logistic regression model, was developed using the significant parameters $(p<0.05)$ by Zhang et al. method [19]. The bootstrap method with 1000 replicates was used for the internal validity of the model. The validate function in the rms package was used to analyze the bias-corrected c-index that evaluated the predictive discrimination of the model. The c-index is the probability of concordance between predicted probability and response. For the practical insight, the nomogram was evaluated the optimal cut-off point for predictive the binary classifiers (death or living) instead of the death-probability prediction. Using the self-consistency validation, the scale's sensitivity, specificity, positive predictive value (PPV), negative predictive value (NPV), accuracy was determined for death in various cut- off point of the total scores. Moreover, the Receiver Operating Characteristic (ROC) curve and the area under the receiver operating characteristic (AUC) were plotted. Additionally, AUCs were determined that values $\geq 0.9$ are "excellent," $\geq 0.80$ "good," $\geq 0.70$ "fair," and $<0.70$ "poor" [20, 21].

\section{Statistical Analysis}

The mean, with standard deviation, was calculated from descriptive purposes. The binary logistic regression analysis was used to identify the predictors of death both univariate and multivariable analysis. In multivariable analysis, the forward method was used to check whether predictors deserved to be included in the model. The statistical analysis was performed using the $\mathrm{R}$ version 3.4.0 software (R Foundation, Vienna, Austria). In details, the 'ggplot2'package was used for building the forest plot of odds ratio with 95\% confident interval $(95 \% \mathrm{CI})$ [22]. The 'rms' package was used for creating nomogram [23]. Moreover, ROC and AUC were created by 'PlotROC' package [24].

\section{Results}

\section{Clinical Characteristics}

The baseline characteristics of the study population are presented in Table 1. The study involved 62 
Table 1. Clinical characteristics

\begin{tabular}{|c|c|}
\hline Factor & $\mathbf{N}(\%)$ \\
\hline \multicolumn{2}{|l|}{ Gender } \\
\hline Male & $57(91.9)$ \\
\hline Female & $5(8.1)$ \\
\hline Mean of age (SD)-year & $37.7(15.8)$ \\
\hline Military personnel & $15(24.2)$ \\
\hline \multicolumn{2}{|l|}{ Mechanism } \\
\hline Gunshot injury & $35(56.5)$ \\
\hline Secondary blast injury & $24(38.7)$ \\
\hline Sharp object injury & $3(4.8)$ \\
\hline Suicide & $4(6.5)$ \\
\hline \multicolumn{2}{|l|}{ Glasgow Coma Scale score } \\
\hline $13-15$ & $31(50)$ \\
\hline $9-12$ & $6(9.7)$ \\
\hline $3-8$ & $25(40.3)$ \\
\hline \multicolumn{2}{|l|}{ Pupillary size and light reflex } \\
\hline Fixed and dilated both eyes & $15(24.2)$ \\
\hline Unequal & $5(8.1)$ \\
\hline Normal and reflex both eyes & $42(67.7)$ \\
\hline Hypotension (Blood pressure <90/60) & $22(35.5)$ \\
\hline Anemia & $15(24.2)$ \\
\hline Coagulopathy & $13(21.0)$ \\
\hline Hypoxia & $5(8.1)$ \\
\hline Acidosis & $3(5.3)$ \\
\hline Mean of neutrophil/lymphocyte ratio (SD) & $8.3(8.1)$ \\
\hline \multicolumn{2}{|l|}{ CT scan of the brain } \\
\hline No (Unstable) & $9(14.5)$ \\
\hline Yes & $53(85.5)$ \\
\hline \multicolumn{2}{|l|}{ Plane of track } \\
\hline Coronal & $24(47.1)$ \\
\hline Sagittal & $27(52.9)$ \\
\hline \multicolumn{2}{|l|}{ Entry site $(\mathrm{N}=51)$} \\
\hline Frontal & $19(37.3)$ \\
\hline Temporal & $9(17.6)$ \\
\hline Parietal & $9(17.6)$ \\
\hline Occipital & $8(15.7)$ \\
\hline Maxillary & $4(7.8)$ \\
\hline Orbital & $2(3.9)$ \\
\hline \multicolumn{2}{|l|}{ Pathology $(\mathrm{N}=53)$} \\
\hline Perforating injury & $1(1.6)$ \\
\hline Bihemispheric injury & $9(16.9)$ \\
\hline Multilobar injury & $11(20.7)$ \\
\hline Linear skull fracture & $6(11.3)$ \\
\hline Depressed skull fracture & $32(60.4)$ \\
\hline Basilar skull fracture & $10(18.9)$ \\
\hline Epidural hematoma & $8(12.9)$ \\
\hline Subdural hematoma & $22(41.5)$ \\
\hline Contusion & $24(45.3)$ \\
\hline Brainstem & $1(1.6)$ \\
\hline Subarachnoid hemorrhage & $23(43.4)$ \\
\hline Intraventricular hemorrhage & $5(9.43)$ \\
\hline Cistern effacement & $13(24.5)$ \\
\hline Diffuse brain edema & $9(17.0)$ \\
\hline Mean of midline shift (SD)-mm & $1.6(2.9)$ \\
\hline \multicolumn{2}{|l|}{ Surgery } \\
\hline No & $25(40.3)$ \\
\hline Decompressive craniectomy with debridement & $12(19.4)$ \\
\hline Craniotomy with debridement & $24(38.7)$ \\
\hline Mastoid approach for foreign body removal & $1(1.6)$ \\
\hline Discharge mortality & $20(32.3)$ \\
\hline
\end{tabular}

individuals enrolled. More than half of them were gunshot injury at the head, whereas penetrating injury from flak of explosion found more than one-third of them. Additionally, PTBI from suicidal attempt was $6.5 \%$ of cases while injury from secondary blast effect was $38.7 \%$. The mean age of the study population was 37.7 (SD 15.8) years. The percentage of the male was $91.9 \%$ of the study population. Concerning severity, $40.3 \%$ of the cases were severe TBI, while $50.0 \%$ had mild TBI. The secondary brain insults, particularly hypotension and hypoxia, were observed at $35.5 \%$ and $8.1 \%$, respectively. $14.5 \%$ of the PTBI patients, who developed persistent instability of their vital signs, did not acquire the CT of the brain. In neuroimaging parameters, two-thirds of cases had the coronal plane of penetrating trajectory while the frontal region was the most common entry site of bullets/flakes. Depressed skull fracture was the most common intracranial pathology observed in neuroimaging. Multilobar injuries, bihemispheric injuries, and perforating injuries were $20.7 \%, 16.9 \%$, and $1.6 \%$, respectively. Therefore, almost two-thirds of cases underwent to operations and mortality rate of the present study at hospital discharge was $32.3 \%$ of cases.

\section{Factors Associated with Mortality}

As the results, the univariate analysis revealed that severe TBI (Odds ratio [OR] 80.7, $p<0.001$;), normal pupils' reactivity to light (OR $0.04, p<0.001$ ), hypotension (OR 9.91, $p<0.001$ ), Hypoxia (OR 10.2, $p=0.04$ ), bihemispheric injuries (OR 19.0, $p=0.001$ ), multilobar injuries (OR 21.5, $p<0.001)$, subarachnoid hemorrhage $[\mathrm{SAH}](\mathrm{OR} 6.9, p=0.02)$, intraventricular hemorrhage [IVH] (OR 26.6, $p=0.006)$, basal cistern effacement (OR 28.8, $p<0.001$ ), midline shift $>5 \mathrm{~mm}$ (OR 19.0, $p<0.001$ ) were significantly associated with death as shown in Table 2. In multivariable analysis, hypotension (OR 8.82, $p=0.03$ ), normal pupils' reactivity to light (OR $0.07, p=0.01$ ), midline shift $>5 \mathrm{~mm}(\mathrm{OR} 18.23, p<0.007)$ were significantly associated with death by backward stepwise method as shown in Table 3.

\section{Nomogram Development and Validation}

As show in Figure 1, the use of the nomogram is simple. For example, a 45-year-old male suffered from gunshot wound at the head. At emergency department, his clinical characteristics were GCS score 3 , bilateral fixed and dilated pupils (71 points), initial blood pressure was $120 / 70 \mathrm{mmHg}$ (0 points). After resuscitation, his CT of the brain showed the entry site of bullets was the right parietal area, bihemispheric injuries, multilobar injuries, $\mathrm{SAH}$, IVH, midline shift $6 \mathrm{~mm}$ to the right. (60 points) as shown in Figure 2. Therefore, he will get a total point value of 131, which approximately corresponds to more than $50-60 \%$ probability of death at hospital discharge.

The calibration plot showed that the model was very 
Table 2. Univariate analysis for the mortality in patients with penetrating brain injury

\begin{tabular}{|c|c|c|}
\hline Factor & Odds ratio $(95 \% \mathrm{CI})$ & $p$ value \\
\hline \multicolumn{3}{|l|}{ Glasgow Coma Scale score } \\
\hline $9-15$ & Ref & \\
\hline $3-8$ & $80.7(9.37-695.53)$ & $<0.001$ \\
\hline \multicolumn{3}{|l|}{ Pupil reactivity } \\
\hline Non-BE & Ref & \\
\hline $\mathrm{BE}$ & $0.04(0.01-0.17)$ & $<0.001$ \\
\hline \multicolumn{3}{|l|}{ Laboratory } \\
\hline Anemia & $3.20(0.91-11.24)$ & 0.06 \\
\hline Hypotension & $9.91(2.90-33.85)$ & $<0.001$ \\
\hline Нypoxia & $10.2(1.06-98.83)$ & 0.04 \\
\hline Coagulopathy & $7.7(2.00-30.14)$ & 0.003 \\
\hline \multicolumn{3}{|l|}{ Plane of track } \\
\hline Coronal & Ref & \\
\hline Sagittal & $0.86(0.21-3.44)$ & 0.83 \\
\hline \multicolumn{3}{|l|}{ Neuroimaging findings } \\
\hline Bihemispheric injuries $^{\mathrm{a}}$ & $19.0(3.37-106.84)$ & 0.001 \\
\hline Multilobar injuries $^{\mathrm{a}}$ & $21.5(3.93-118.26)$ & $<0.001$ \\
\hline Subarachnoid hemorrhage ${ }^{a}$ & $6.9(1.29-37.0)$ & 0.02 \\
\hline Intraventricular hemorrhage ${ }^{a}$ & $26.6(2.53-280.5)$ & 0.006 \\
\hline Subdural hemorrhage $\mathrm{e}^{\mathrm{a}}$ & $2.42(0.65-9.01)$ & 0.18 \\
\hline Contusion ${ }^{\text {a }}$ & $0.82(0.22-3.03)$ & 0.77 \\
\hline Basal cistern effacement ${ }^{\text {a }}$ & $28.8(4.71-175.97)$ & $<0.001$ \\
\hline \multicolumn{3}{|l|}{ Midline shift } \\
\hline$<5 \mathrm{~mm}$ & Ref & \\
\hline$\geq 5 \mathrm{~mm}$ & $19.0(3.3-106.84)$ & $<0.001$ \\
\hline
\end{tabular}

a Data show only "yes group" while reference groups (no group) are hidden

Table 3. Multivariate analysis

\begin{tabular}{lll}
\hline Factor & Odds ratio $\mathbf{9 5 \%} \mathbf{C I})$ & $\boldsymbol{p}$ value \\
\hline Hypotension & & \\
No & Ref & 0.03 \\
Yes & $8.82(1.11-69.85)$ & \\
Pupil reactivity & Ref & 0.01 \\
Non-BE & $0.07(0.01-0.62)$ & \\
BE & & 0.007 \\
Midline shift & Ref & \\
$<5 \mathrm{~mm}$ & $18.23(2.22-149.52)$ & \\
$\geq 5 \mathrm{~mm}$ & & \\
\hline
\end{tabular}

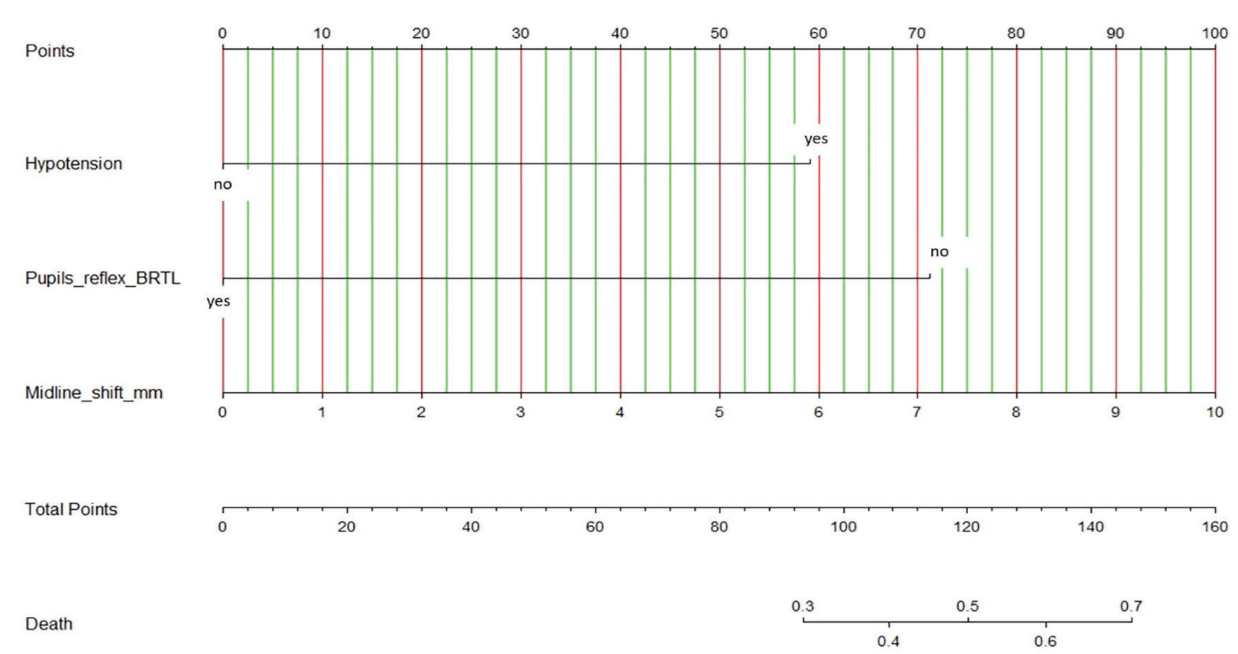

Fig. 1. Nomogram predicting the mortality in penetrating traumatic brain injury. To use the nomogram, draw a straight line upward from the patient's characteristics such as SHI, pupils reflex, SAH, IVH to the upper points scale, the sums of the scores of all variables. Then, draw another straight line down from the scale of the total points through the risk of death. This is the probability of the presence of death in an individual. Abbreviation: BRTL; Both pupils react to light, mm; millimeter 


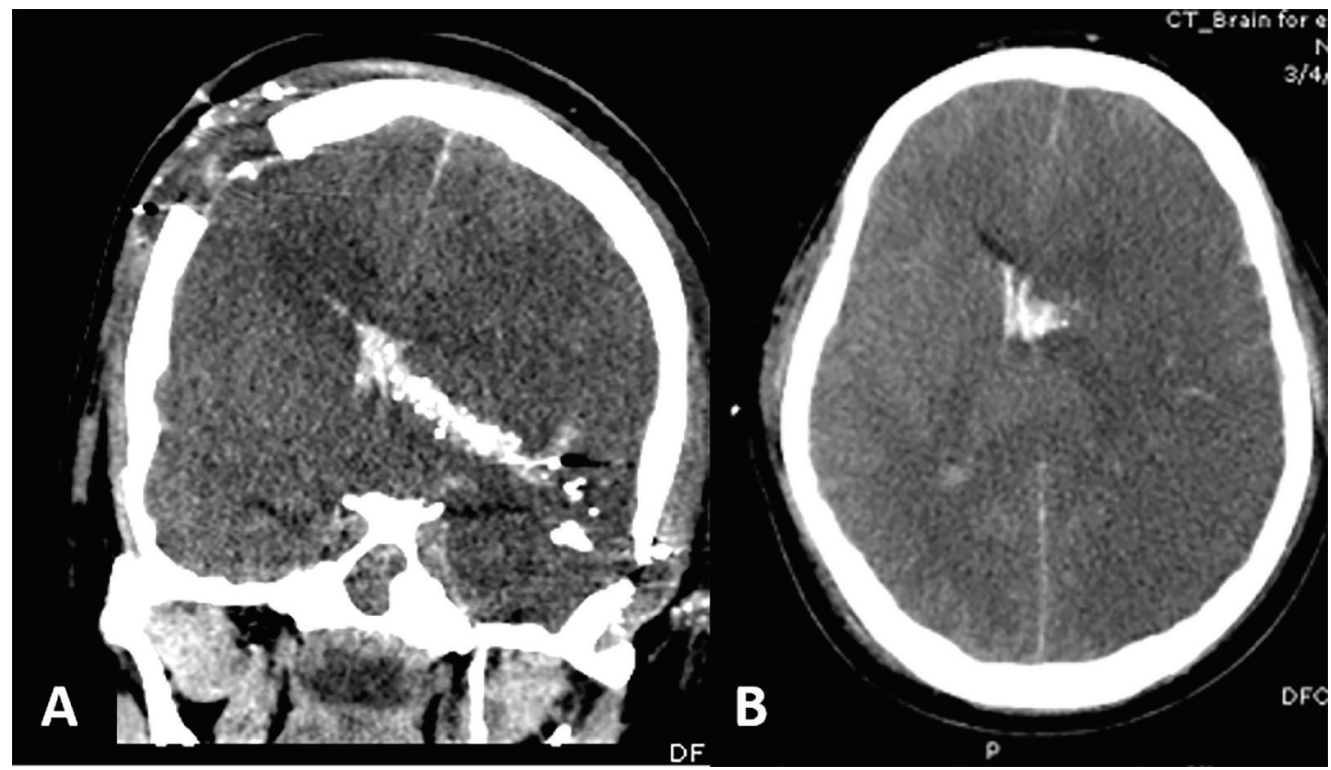

Fig. 2. Perforating injury. (A) Coronal plane CT of the brain shows bullets pass at the right parietal area and cross through multilobar involvement. Finally, the bullets exit through at left temporal area. (B). Axial CT of the brain showed diffuse brain swelling, intraventricular hemorrhage, and subarachnoid hemorrhage.

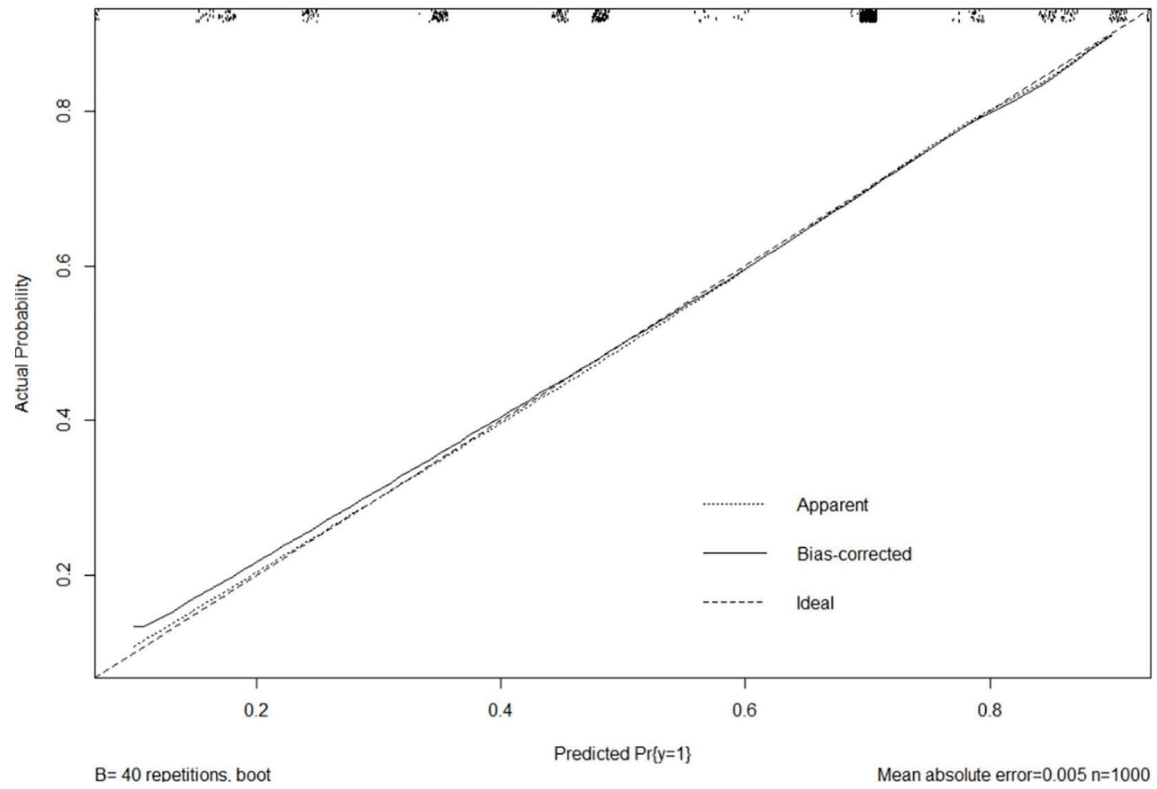

Fig. 3. Bootstrapped calibration plot, which proves that concordance between the predicted probability and response is satisfactory.

close to the ideal Figure 3 and had a bias-corrected c-index value of 0.867 . For general application, validation of the predictive nomogram was evaluated as the binary classifiers (death or living at hospital discharge) instead of the predicted probability of death. Therefore, we proposed the optimal cut-off point of the total scores of this nomogram to predict the hospital-discharge mortality. As the results, the scale's sensitivity, specificity, PPV, NPV were demonstrated in Table 4 and ROCs, and AUCs were revealed in Figure 4. As the results, the optimal cutoff points for predicting hospital-discharge was the 100 scores because this cut-off point which had the highest sensitivity, specificity, PPV, NPV, accuracy and AUC.

\section{Discussion}

Penetrating brain injury is one of the most challenging clinical entities for neurosurgeons. The present study concerned the mortality of patient with PTBI. Overall mortality rate of the present study was $32.3 \%$, while previous studies reported mortality of PTBI range 21-88\%. Causally, our series included various penetrating mechanisms such as a gunshot, secondary blast effect, and a stab wound to the head. Hofbauer et al. reported that the mortality rate of a gunshot wound to the head was $87 \%$ while the mortality rate of the non-gunshot wound injuries was $4 \%[7,25]$.

Several studies have been reported the various 
Table 4. Optimizing cut-points for prediction of mortality

\begin{tabular}{|c|c|c|c|c|c|c|}
\hline Cut-off point & Sensitivity & Specificity & $\mathrm{PPV}^{\mathrm{a}}$ & $\mathbf{N P V}^{\mathbf{b}}$ & Accuracy & $\mathrm{AUC}^{\mathrm{d}}$ \\
\hline 90 & 80.0 & 87.8 & 61.5 & 94.7 & 86.2 & 0.84 \\
\hline 100 & 80.0 & 92.6 & 72.7 & 95.0 & 90.2 & 0.86 \\
\hline 110 & 70.0 & 92.6 & 70.0 & 92.6 & 88.2 & 0.81 \\
\hline 120 & 70.0 & 95.1 & 77.7 & 92.8 & 90.2 & 0.83 \\
\hline 130 & 60.0 & 95.1 & 75.0 & 90.7 & 88.2 & 0.78 \\
\hline 140 & 70.0 & 95.2 & 77.7 & 92.8 & 90.2 & 0.62 \\
\hline 150 & 80.0 & 95.1 & 80.0 & 95.1 & 92.1 & 0.57 \\
\hline
\end{tabular}

${ }^{\mathrm{a} P P V}$ : positive predictive value, ${ }^{\mathrm{b}} \mathrm{NPV}$ : negative predictive value, ${ }^{\mathrm{c}} \mathrm{ROC}$ : Receiver Operating Characteristic curve, ${ }^{\mathrm{d}} \mathrm{AUC}$ : area under the receiver operating characteristic

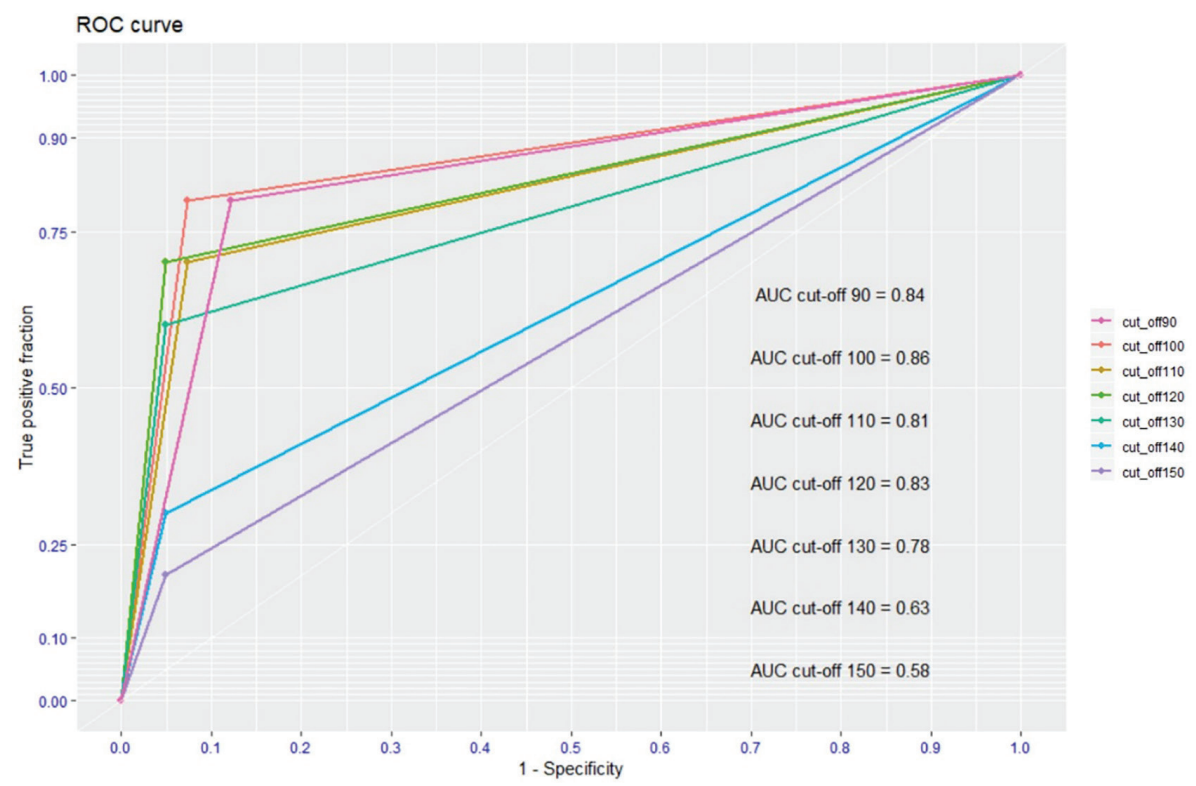

Fig. 4. The Receiver Operating Characteristic (ROC) curve and the area under the receiver operating characteristic (AUC) of each cut-point of the nomogram.

prognostic factors influencing the mortality of PTBI. Lower GCS, bilateral fixed and dilated pupils are the common the significant prognostic factors which have been reported [26]. Moreover, hypotension and anemia were described that these parameters associated with increased mortality by Decuypere et al., [27]. In accordance with the previous studies, the results of the present study revealed the clinical parameters were: lower GCS, bilateral mydriasis, hypotension, and anemia. The absence of pupil reactivity in general confirms the brainstem function cruelly compromised, whereas patients with normal pupil reactivity reflex correlating with an undamaged function of brainstem. Additionally, hemorrhagic shock and anemia can have observed in severe TBI and caused compromised cerebral perfusion [27, 28]. Additionally, Maragkos reported suicide-related PTBI is significantly associated with mortality. Conversely, this factor was not significant predictors because of the small proportion of suicidal attempt in our cohort [28].

Aspects of the missile/flak track, which have been studied for prognostic value, include the presence of bihemispheric lesions, multilobar involvement, and ventricular involvement. Additionally, cerebral contusion, SAH, IVH, SDH, and evidence of increased intracranial pressure (cistern effacement, and midline shift) related significantly with increased mortality and an unfavorable outcome $[10,11]$. In the same way, the results of the present study were mainly accordant with other studies.

The predicted model from logistic regression analysis has been presented in various methods, including score chart, web-based calculator, and nomogram. Muehlschlegel et al. proposed the SPIN score for predicting survival after PTBI with various options of predicting model [11]. Besides, Bendt et al. developed the St. Louis Scale for Pediatric Gunshot Wounds to the Head [10]. The St. Louis Scale were externally validated by Decuypere et $a l$. ., Based on data from the 71 patients in this study, the sensitivity, specificity, positive predictive value, and negative predictive value of the St. Louis scale in predicting death (score $\geq 5$ ) were $94.1 \%, 75.6 \%$, $78 \%$, and $93.3 \%$, respectively [27].

The nomogram is one of methods to present the predicted model as the graphic scoring. We used this method because the nomogram is the simple and easy to implication in the clinical practice. Moreover, we defined the optimal cut-off point of 
this nomogram for predicting the mortality. As the results, the AUCs showed that 100 scores were the optimal cut-off point for predicting the risk of death. Moreover, the sensitivity, specificity, positive predictive value, and negative predictive value of the present nomogram in predicting mortality (total score $\geq 100$ ) were $80 \%, 92.6 \%, 72.7 \%, 95.0 \%$, and 0.86 respectively.

Finally, certain limitations of the present study should be acknowledged. The retrospective design may have led to bias and an inability to control confounding factors [29]. However, we tried to tackle this limitation by employing a multivariable analysis. Additionally, the nomogram needs the external validation in the future because this is the first paper proposed the first nomogram of PTBI as our knowledge.

In conclusion, PTBI is the fatal injury depend on both clinical and neuroimaging parameters. The nomogram is the alternative method presenting the prognostic model providing prognostic parameters toward implication for clinical decision making.

Conflicts of Interest: None declared.

\section{References}

1. Tunthanathip T, Phuenpathom N. Impact of Road Traffic Injury to Pediatric Traumatic Brain Injury in Southern Thailand. JNeurosci Rural Pract. 2017;8(4):601-608

2. Larkin MB, Graves EKM, Boulter JH, Szuflita NS, Meyer RM, Porambo $\mathrm{ME}$, et al. Two-year mortality and functional outcomes in combatrelated penetrating brain injury: battlefield through rehabilitation. Neurosurg Focus. 2018;45(6):E4.

3. Wallace SA, Meyer M, Stephens FL Armonda RA, Aarabi B, Bell RS. Traumatic and penetrating head injury. In: Winn HR, editor. Youmans Neurological Surgery. 7th ed. Philadelphia: Saunders, The Curtis Center 2017. P. 2922-32.

4. Alvis-Miranda HR, M Rubiano A, Agrawal A, Rojas A, MoscoteSalazar LR, Satyarthee GD, et al. Craniocerebral Gunshot Injuries; A Review of the Current Literature. Bull Emerg Trauma. 2016;4(2):65-74.

5. Aarabi B, Tofighi B, Kufera JA, Hadley J, Ahn ES, Cooper C, et al. Predictors of outcome in civilian gunshot wounds to the head. $J$ Neurosurg. 2014;120(5):1138-46

6. Gressot LV, Chamoun RB, Patel AJ, Valadka AB, Suki D, Robertson CS, et al. Predictors of outcome in civilians with gunshot wounds to the head upon presentation. J Neurosurg. 2014;121(3):645-52

7. Hofbauer M, Kdolsky R, Figl M, Grünauer J, Aldrian S, Ostermann RC, et al. Predictive factors influencing the outcome after gunshot injuries to the head-a retrospective cohort study. J Trauma. 2010;69(4):770-5.

8. Fathalla H, Ashry A, El-Fiki A. Managing military penetrating brain injuries in the war zone: lessons learned. Neurosurg Focus. 2018;45(6):E6.

9. Splavski B, Vranković D, Saftić R, Muzević D, Kosuta M, Gmajnić R. Clinical predictors correlated to outcome of war missile penetrating brain injury. Acta Med Croatica. 2006;60(4):369-73.

10. Bandt SK, Greenberg JK, Yarbrough CK, Schechtman KB, Limbrick DD, Leonard JR. Management of pediatric intracranial gunshot wounds: predictors of favorable clinical outcome and a new proposed treatment paradigm. $J$ Neurosurg Pediatr. 2012;10(6):511-7.

11. Muehlschlegel S, Ayturk D, Ahlawat A, Izzy S, Scalea TM, Stein DM, et al. Predicting survival after acute civilian penetrating brain injuries: The SPIN score. Neurology. 2016;87(21):2244-2253.

12. Graefen M, Karakiewicz PI, Cagiannos I, Hammerer PG, Haese A, Palisaar J, et al. A validation of two preoperative nomograms predicting recurrence following radical prostatectomy in a cohort of European men. Urol Oncol. 2002;7(4):141-6.

13. Liang $\mathrm{W}$, Zhang L, Jiang G, Wang Q, Liu L, Liu D, et al. Development and validation of a nomogram for predicting survival in patients with resected non-small-cell lung cancer. J Clin Oncol. 2015;33(8):861-9.

14. Devin CJ, Bydon M, Alvi MA, Kerezoudis P, Khan I, Sivaganesan A, et al. A predictive model and nomogram for predicting return to work at 3 months after cervical spine surgery: an analysis from the Quality Outcomes Database. Neurosurg Focus. 2018;45(5):E9.

15. Dogan HS, Altan M, Citamak B, Bozaci AC, Karabulut E, Tekgul S. A new nomogram for prediction of outcome of pediatric shockwave lithotripsy. J Pediatr Urol. 2015;11(2):84.e1-6.

16. Tunthanathip T, Sae-Heng S, Oearsakul T, Sakarunchai I, Kaewborisutsakul A, Taweesomboonyat C. Machine learning applications for the prediction of surgical site infection in neurological operations. Neurosurg
Focus. 2019;47(2):E7.

17. Manley G, Knudson MM, Morabito D, Damron S, Erickson V, Pitts L. Hypotension, hypoxia, and head injury: frequency, duration, and consequences. Arch Surg. 2001;136(10):1118-23.

18. Wu X, Du Z, Yu J, Sun Y, Pei B, Lu X, et al. Activity of factor VII in patients with isolated blunt traumatic brain injury: association with coagulopathy and progressive hemorrhagic injury. J Trauma Acute Care Surg. 2014;76(1):114-20.

19. Zhang Z, Kattan MW. Drawing Nomograms with R: applications to categorical outcome and survival data. Ann Transl Med. 2017;5(10):211.

20. Swets JA. ROC analysis applied to the evaluation of medical imaging techniques. Invest Radiol. 1979;14(2):109-21.

21. Gergen KJ, Morse SJ, editors. Self-consistency: Measurement and validation. Proceedings of the Annual Convention of the American Psychological Association: American Psychological Association; 1967.

22. Wickham H, Chang W, Henry L. Package 'ggplot2'. [Last accessed: 29 JAN 2019]. Available from: https:// cran.r-project.org/web/packages/ ggplot2/ggplot2.pdf.

23. Harrell Jr FE. Package 'rms'. 2019. [Last accessed: 29 JAN 2019]. Available from: https://cran.r-project. org/web/packages/rms/rms.pdf.

24. Sachs MC, Corty RW. Package 'plotROC' 2019. [Last accessed: 29 JAN 2019]. Available from: https:// cran.r-project.org/web/packages/ plotROC/plotROC.pdf.

25. Tunthanathip $\mathrm{T}$, Khocharoen $\mathrm{K}$, Phuenpathom N. Blast-induced traumatic brain injury: the experience from a level I trauma center in southern Thailand. Neurosurg Focus. 2018;45(6):E7.

26. Mauritz W, Leitgeb J, Wilbacher I, Majdan M, Janciak I, Brazinova 
A, et al. Outcome of brain trauma patients who have a Glasgow Coma Scale score of 3 and bilateral fixed and dilated pupils in the field. Eur $J$ Emerg Med. 2009;16(3):153-8.

27. DeCuypere M, Muhlbauer MS, Boop FA, Klimo P Jr. Pediatric intracranial gunshot wounds: the Memphis experience. J Neurosurg Pediatr. 2016;17(5):595-601.

28. Maragkos GA, Papavassiliou E, Stippler M, Filippidis AS. Civilian Gunshot Wounds to the Head: Prognostic Factors Affecting Mortality: Meta-Analysis of 1774 Patients. J Neurotrauma.
2018;35(22):2605-14.

29. Mann CJ. Observational research methods. Research design II: cohort, cross sectional, and casecontrol studies. Emerg Med J. 2003;20(1):54-60. and share. Bulletin of Emergency And Trauma articles are published under a Creative Commons license (CC-BY-NC). 